\title{
HOME I/O and FACTORY I/O
}

\section{Pieces of innovative PO simulation software for automation education}

\author{
A. Philippot, B. Riera, M. Koza, R. Pichard, R. \\ Saddem, F. Gellot, D. Annebicque \\ CReSTIC (EA3804), University of Reims Champagne- \\ Ardenne (URCA) \\ Moulin de la Housse, BP 1039, 51687 Reims, France \\ bernard.riera@univ-reims.fr
}

\author{
Fabien Emprin \\ CEREP (EA 4692), University of Reims Champagne- \\ Ardenne (URCA) \\ 23 rue Clément Ader, 51100 Reims, France \\ fabien.emprin@univ-reims.fr
}

\begin{abstract}
Since 2008, the CReSTIC of the University of Reims Champagne Ardenne (URCA), has collaborated with Real Games, a Portuguese company, within the frame of a scientific and technical partnership towards the development of innovative operative part simulation software based on the use of video game technologies (graphical and audio rendering, « game play », interactivity and attractiveness). These simulators which are a part of a type of serious games, can be connected to physical control utilities (Programmable Logic Controller, Microcontroller...) or software utilities (LabView, Matlab...) which facilitates education in automation. In this paper two new pieces of simulation software are presented, HOME I/O (the virtual house) and FACTORY I/O (the virtual factory). A survey has been conducted by users of these two softwares in 2016, together with a science of education lab (CEREP) as well as 77 bachelor's degree, CUBGE and Engineering students from URCA. The obtained results are presented in this paper, and show the interest these digital tools have for education of Automation.
\end{abstract}

Keywords—plant simulation; automation; serious games; experience return

\section{INTRODUCTION}

Serious games are considered as a potential if not major modality for the education for the «Millennials», also named « digital native », who spend more time in front of a console or their computer screen than the television. Serious games distinguish themselves by combining a serious dimension (Education in our case) with a playful dimension $[1,2]$. In other words, the goal is to use the fundamental principles of videogames (exploring, challenges, rewards, learning...) in order to motivate students and to direct their centers of interest towards particular educations. The rise of serious games comes from the video game development sector, of which the Turnover exceeds that of cinema and music nowadays. In the context of school, serious games ask the fundamental question of the role assigned to the teacher and the way to effectively incorporate them into an educational sequence in class. It is why the real stake is to develop digital tools adapted to students, which are effective from an educational standpoint, and that incorporate themselves into innovative pedagogical applications where the teacher has their role.

The conception of a digital tool encouraging inquiry and allowing the teacher to imagine and set up multiple situations and difficulties is the vision that has led to the development of software like HOME I/O and FACTORY I/O in a scientific and technical cooperation between the CReSTIC of the University of Reims Champagne Ardenne (URCA) and the Portuguese company Real Games (www.realgames.co), since 2008. The use of technologies based on videogames (Graphical and audio rendering, interactivity and attractiveness) is seen as a means to promote the «Awareness of the situation», the motivation of students, and therefore promoting their learning in this approach.

Computer simulations are also used in order to reduce risks, costs and optimize time spent on education (by accelerating the acquisition of experience or by changing the arrangements of the education through remote training). In our case, the serious game is considered first and for all as a digital tool which the teacher will be able to use in the frame of his own pedagogic scenarios, therefore encouraging multiple uses. One of our hypotheses, which separate us from many other tools, is the importance of the playability (the «game play») which has to reach gaming standards that the Millennials are fond of.

The first part of the paper presents the software called HOME I/O, developed during a 3-year project financed by the Ministry of National Education and Higher Education and Research (MENESR) and lead by the CReSTIC. The initial idea has been to bring a whole house into the classroom. This virtual house becomes a place discovery for technological and scientific engineering in general and automation in particular through the ways of a first person shooter (FPS). This virtual home is usable from Middle School to University. Owning a «real» house in educational institutions is impossible because of obvious costs, space and feasibility issues. The second part of the paper presents FACTORY I/O. This program allows the building of your own virtual factory by assembling subsystems, which are available in a components library, and the interfacing with physical or digital Programmable Logic Controllers (PLC). FACTORY I/O, just as HOME I/O, is a first person simulation, and is based on the same technology.

The third and last part of the paper presents survey conducted in a partnership between the laboratory of sciences of education CEREP of the URCA in order to evaluate the usefulness, usability and acceptability of those two programs, the survey was conducted with 77 students from three different 
educations. The obtained results are promising and show the interest these innovative digital tools bring for the education in automation.

\section{HOME I/O: THE VIRTUAL HouSE}

HOME I/O (https://realgames.co/home-io/) is the result of «DOMUS» (2011-2014) a 3-year research and development project between the CReSTIC lab from the University of Reims Champagne-Ardenne and Real Games, a Portuguese company, which was partially founded by the French Ministry of National Education, [3]. HOME I/O is real time simulation software (figure 1) of a smart house and its surrounding environment [4]. This software was built to cover a large spread of educational applications in technology and engineering sciences. The designing of HOME I/O places the teacher and student in the heart of the procedure.
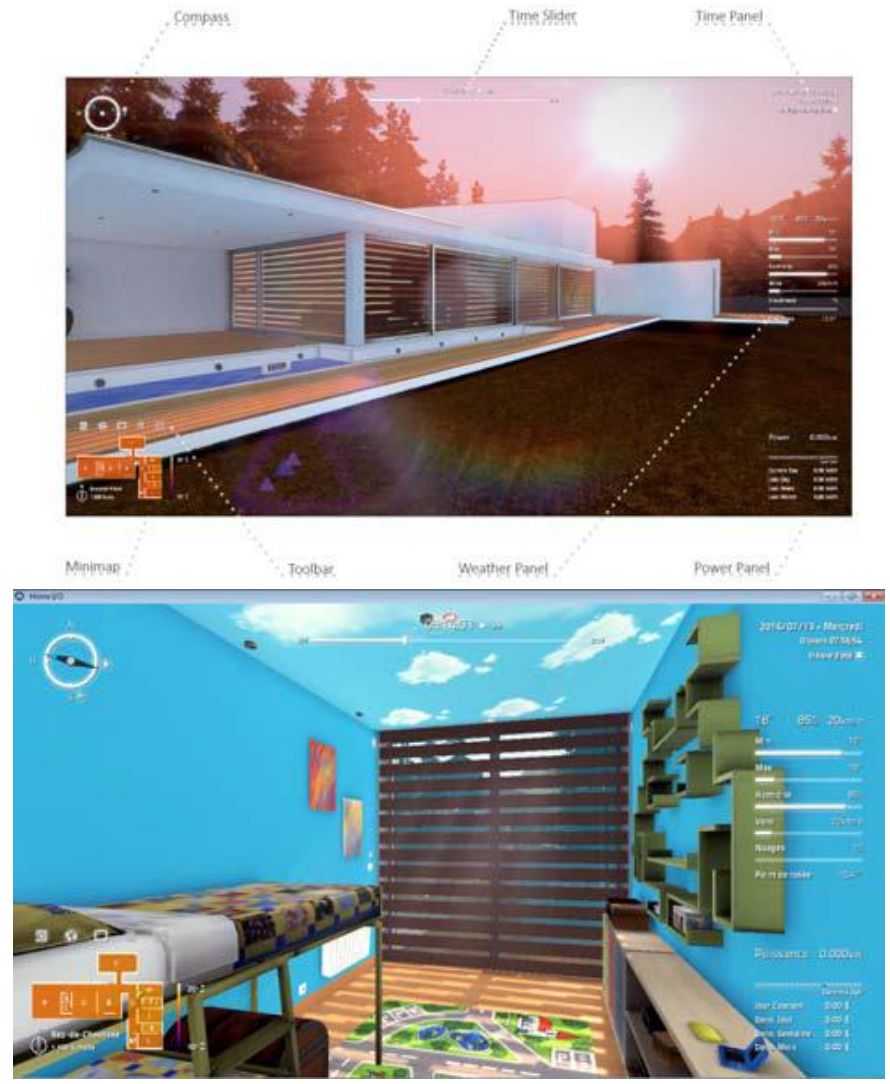

fig 1: HOME I/O

More than a simulator, HOME I/O is a learning, experimenting and project development environment dedicated to the student. The National Resource Network (Réseau National de Resources - RNR), the Academic delegation to digital (Délégation académique au numérique - DAN) and the Rectorship of Reims have supported DOMUS through its test and evaluation phases. The initial Specifications specified that the developed program had to be usable in Middle School in technology classes and complement Web resources and currently available tools, in particular for the 8th grade classes of «Comfort and Home Automation».

The Virtual House had to also be suitable for High School and in particular the STI2D section. In Middle School, the program had to be autonomous and not require other applications in order to function. On the other hand, for High School and Higher Education, the house is seen as a source of data capable of interfacing with third party utilities, software (LabView, Matlab...) or hardware (microcontrollers, programmable logic controllers...). The idea was therefore to provide an educational tool contributing to the continuity of STEM education, from middle schools to Universities. HOME I/O was built to study the house with different points of view (automation, energetic efficiency, smart home...), in its entirety or in subsystems. The complexity can therefore be adapted to various levels and pedagogic objectives.

The stages of conception were based on a deep study of needs. A technical study of home automation and the smart home was conducted. This study has shown that the house cannot be considered and studied separately from its external environment. Indeed, home automation scenarios have to take into account geographical and meteorological conditions. This multi-physical vision incidentally allows to link the technology together with other scientific fields (mathematics, physical sciences and natural sciences). On the other hand, this leads to issues with the modelling (heat transfer, sun position, lighting...), particularly when a real time simulation is desired. In order to meet that objective, it is possible with HOME I/O to place the house anywhere on earth, and the position of the sun (and therefore the lighting) will be realistic taking into account the date and time of the day (Which can be set). Additionally, changing meteorological conditions is also possible (wind strength and orientation, cloud coverage, humidity and minimum and maximum temperatures over the day). These environmental settings impact on interior temperature and lighting. A simplified model was therefore created in order to allow the simulation of real time heat transfer. This model includes radiation, convection, conduction phenomena and takes physical properties of materials into account (noneditable).

This includes the simulation of exchanges between air groups at different temperatures. The model is influenced by disturbances such as those the opening of doors and windows represent. The external air temperature influences the temperature of the house (heat transfer and airflow). Wind facilitates heat transfer between the house and the outside. Walls which are facing wind are more reactive to heat transfer with the outside. Cloud coverage reduces the effects of radiation from the sun and sky.

Finally, humidity changes the dew point, which influences the way outside air plays in the inside temperature.

Pedagogy is the main goal set with HOME I/O. The point is to set up a house which can be similar to a «black box» for studies, and can be a place of experiments and source of data. In HOME I/O, dynamic models are purely descriptive, and don't allow for dimensioning. Inside of a house, physical phenomena have very different dynamics. For instance, a garage door or a rollup shutter close in a few seconds. On the other hand, reaching the steady state of the temperature of a room can take up to several hours. It is therefore fundamental to have the option of accelerating time, which HOME I/O does. There are four different simulation speeds; the fastest one 
allows the simulation of 24 hours to pass in only 17 seconds. It is possible to control lighting, shutters, electrical heating and an alarm system against home intrusion as well as fire prevention with HOME I/O. In total, HOME I/O offers 174 interactive objects (figure 2) (lights, switches, dimmers, rollup shutters, gate, garage door, sirens, presence sensors, lighting sensors, fire detectors, door opening sensors, remote control, heaters, thermostats) which can be used to automate the house or as logic or digital data source.

For instance, it is possible to know and monitor electrical consumption. The functional realism is just as important as the graphical rendering. The principle of a home automation system is to centralize the control and command. As opposed to a regular electrical setup, the command and power circuits are separated. Therefore, it becomes possible to establish links between the command organs and receivers which usually are separate subsystems. Thanks to HOME I/O, the student will be able to assume two roles: The designer of the home automation system, and its user. Every controllable object can be used in three distinct modes: Wired, Console or External.

- In the wired mode, the house isn't automated. It's a simple electrical setup where the entirety of the appliances is wired.

- In the console mode (or simplified home automation mode), controllable objects are programmable in a way similar to home automation boxes, by setting up scenarios (lighting, motorization, heating, home security and home automation security). This mode is particularly suited for Middle School, since the functional aspect of the intelligent home can easily be specified, and grasped by the students, without going into too many technicalities.

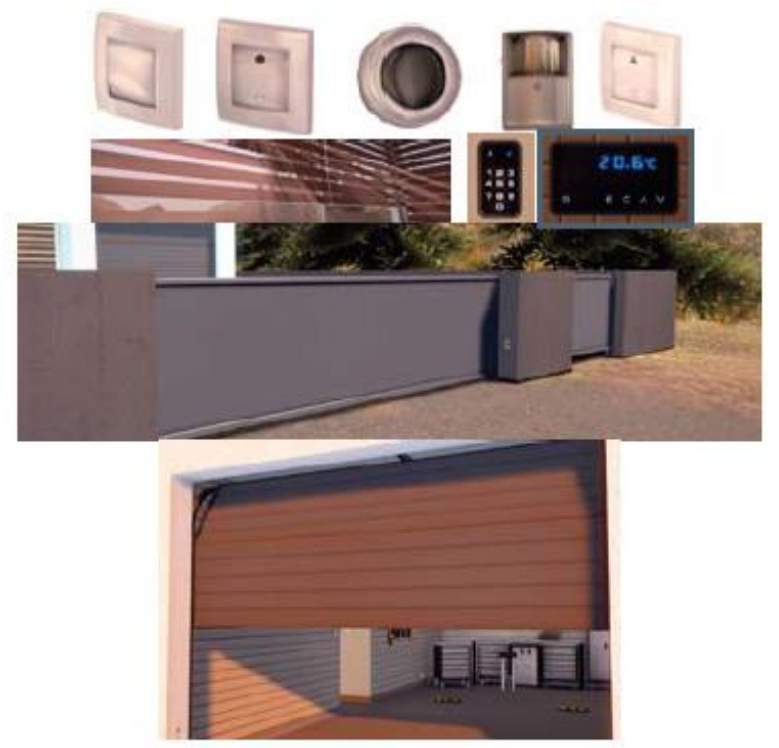

fig 2: HOME I/O

- In the external mode, the inputs/outputs of each object can be used with the CONNECT I/O software, or third party technologies (software or hardware) through an SDK (figure 3). CONNECT I/O is a software PLC which allows the creation of graphical control applications for HOME I/O among other things. They can communicate through all kinds of plugins (Modbus server TCP, OPC server...) or via hardware (Arduino, DAQ, Picaxe...). The main function blocs of the IEC 61131-3 standard for programmable logic controllers (PLC) - logic and arithmetic operations, counters, delays, rising/falling edge, compare blocs... - are available, and CONNECT I/O even allows the connection between different technologies, be it software or hardware. The programming is realized by click and dragging and linking different objects. This opening (through CONNECT I/O or the SDK) increases the applications of HOME I/O. It becomes possible (and easy) to pilot the virtual house from a smartphone (by using Modbus TCP servers for instance) or to control the lighting of a room with LabView... The external mode is particularly suitable for High School and Higher Education.

One of the steps of the DOMUS project was to question the appropriation of the tool by the teachers at the end of the development. Training sessions have been offered, as well as analyzed in order to understand teacher's standpoint on the tool and the distribution among the teaching community [5].

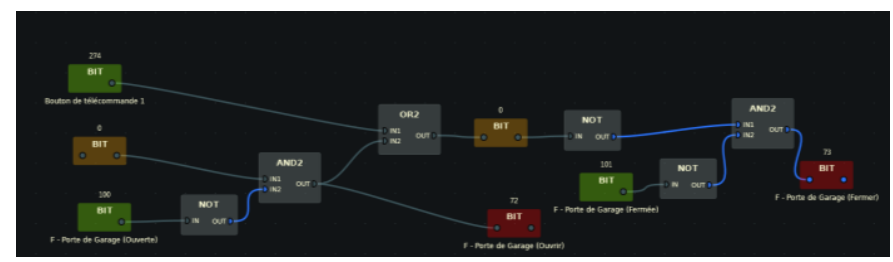

fig 3: CONNECT I/O

HOME I/O has been recognized as pedagogically interesting by the MENESR, and has received the "Coup de Coeur" award in the "Higher Education" category during the 6 th edition of "TROPHEES DES TECHNOLOGIES EDUCATIVES 2014" in the center EDUCATECEDUCATICE in Paris. Nowadays, HOME I/O is being used by around 500 institutions (Middle Schools, High Schools and Universities) in France. At the University of Reims Champagne Ardenne, HOME I/O is used for practical courses in combinational logic for first and third year bachelors, technical degrees majoring in packaging and conditioning and its engineering degree.

\section{FACTORY I/O: THE VIRTUAL PLANT}

FACTORY I/O (https://factoryio.com/) is a new generation of industrial system 3D simulation for programmable logic controllers (PLC) and automation training. FACTORY I/O is meant for technical and professional education (High Schools, 2-year degrees, Engineering schools, bachelors, masters degrees...). FACTORY I/O uses the same technologies as HOME I/O, and is the successor of the program called ITS PLC [4]. FACTORY I/O contains several important improvements:

- The ability to build your own plant from a library of standardized parts which are found in the industrial scene. FACTORY I/O also contains 20 ready-to-use 
systems (figure 4) which cover a wide range of command applications.

- As opposed to ITS PLC, FACTORY I/O includes both logical and analog inputs and outputs. For instance, it's possible to measure the weight of an object, or to measure the level of a tank/vat. FACTORY I/O is therefore usable for practical courses, both in the field of DES (Discrete Event Systems) as in the field of feedback control.

- FACTORY I/O includes communication drivers capable of directly interfacing with Programmable Logic Controllers (PLCs from the SIEMENS, AllenBradley and Schneider Electric brands), with PLC simulators through Modbus TCP or an OPC server (Codesys), and every other type of utilities (PLC, Microcontrollers...) can be interfaced through logic or analog I/O boxes (DAQ Advantech 4750 and 4704). Finally, it is also possible to interface its own communication drivers though a provided SDK which allows an easy connection with Matlab or LabView.

- FACTORY I/O also includes a PLC software (soft PLC), CONTROL I/O, which enables you to graphically build your own controller without having an external physical or software controller. CONTROL I/O, similarly to CONNECT I/O used with HOME I/O, includes most function blocks from the IEC 61131-3 industrial PLC programming standard - logic and arithmetic operations, counters, delays, rising/falling edge, compare blocs...-

FACTORY I/O enables you to have a virtual plant and logical or analog data source inside of the classroom to train command, PLC, SCADA (Supervisory Control and Data Acquisition), HMI (Human Machine Interface) and MES (Manufacturing Execution System)...

FACTORY I/O offers a complete interactivity with the environment. It is therefore possible to introduce any kind of disturbances or breakdowns on sensors, actuators or objects (boxes, pallets...).

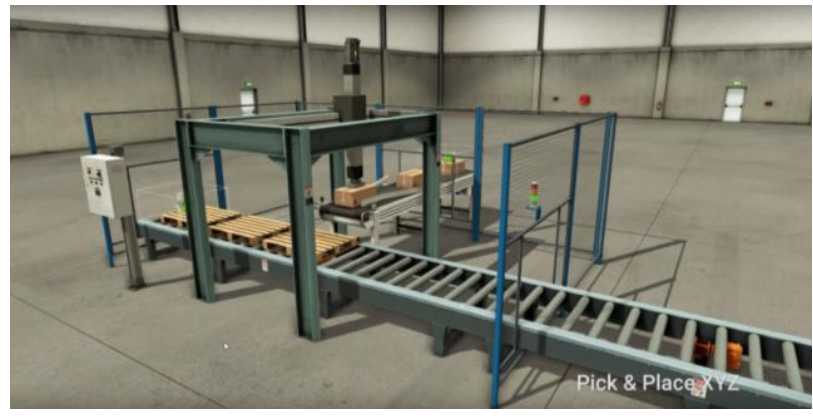

fig 4: « Pick and Place » system of FACTORY I/O

The last part of the paper presents the tests done with the students in order to receive feedback about HOME I/O and FACTORY I/O. Finally, complete content and organizational editing before formatting. Please take note of the following items when proofreading spelling and grammar:

\section{FEEDBACK WITH HOME I/O AND FACTORY I/O}

HOME I/O and FACTORY I/O are used at the URCA for practical courses in combinatory and sequential logic in several classes among which the 3rd year of bachelors in engineering sciences and automation (27 students, FACTORY I/O), 2nd year preparatory classes for higher education (14 students, FACTORY I/O), 1st year of the A2I engineer cycle (URCAUTT, 36 students, HOME I/O). It seemed pertinent to receive the feedback from 77 students through the evaluation of these two simulation tools. These three classes were chosen as test group because: The practical courses had similar length (6 hours), they had the same pedagogic goals (initiation to combinatory and sequential logic), different teachers for the three classes and different practical course subjects.

The assessment of data processing environments for human education (EIAH) can be done through 3 dimensions: Utility, Usability and Acceptability [6]. Utility is defined as the adequacy between the training objective and reaching said objective. Usability is about the ease of use (maneuverability) of the EIAH. Usability is linked to the Human Machine Interface (HMI). Acceptability conditions the decision to use the tool through appropriation. This criterion is therefore closely linked to Utility and Usability of the EIAH. During this test, we wished to evaluate these three criteria through the view of the students, and by additionally trying to show whether the playfulness contributes to Utility and Acceptability or not. The methodology we adopted to evaluate these three criteria consisted in carrying out a survey during the last practical course, 10 questions one of which is open. Students could, if they so wished, stay anonymous. Two identical surveys were made, one for HOME I/O with CONNECT I/O and the other for FACTORY I/O with CONTROL I/O. Figures 5 and 6 show the surveys used respectively for HOME I/O (and CONNECT I/O) and FACTORY I/O (and CONTROL I/O). The goal was to have the students evaluate the Usability and Utility of these programs. A statistical analysis of these surveys was done, the results of which we are now presenting. The answers concerning these two programs are similar except for two questions in which there are significant differences (test $\mathrm{t}$ ).

- For ease of use $(\mathrm{t}=2.93,1-\mathrm{p}=99.5 \%)$, both tools are seen as easy to use, however: For HOME I/O: $96 \%$ of results are relatively easy to very easy. For FACTORY I/O: $70 \%$ of results are relatively easy to very easy.

These results can be explained through the fact that FACTORY I/O is indeed more complex than HOME I/O which has been made to be used for Middle to High School level, and that it is easier for a novice to understand and learn the functionalities of a home than a production line.

- For the playfulness aspect $(\mathrm{t}=2.22, \mathrm{p}-\mathrm{p}=97.2 \%)$ : For FACTORY I/O: $56 \%$ of answers agree that the software is playful compare to $77 \%$ for HOME I/O.

Concerning Usability: if both tools are easy to use and fun HOME I/O is significantly more so in the frame of this test. For all other questions, answers are not significantly diverging; the results are therefore globally presented for HOME I/O and FACTORY I/O. We have found that:

- A good or excellent quality for $99 \%$ of answers; 
- An ease of use and understanding of the functioning: $90 \%$ easy to very easy;

- An easy connection with CONNECT I/O or CONTROL $\mathrm{I} / \mathrm{O}: 85 \%$ relatively easy to very easy;

- CONNECT I/O and CONTROL I/O are considered easy to use: $92 \%$ relatively easy to very easy;

- CONNECT I/O and CONTROL I/O are easy to understand: $87 \%$ relatively easy to very easy.

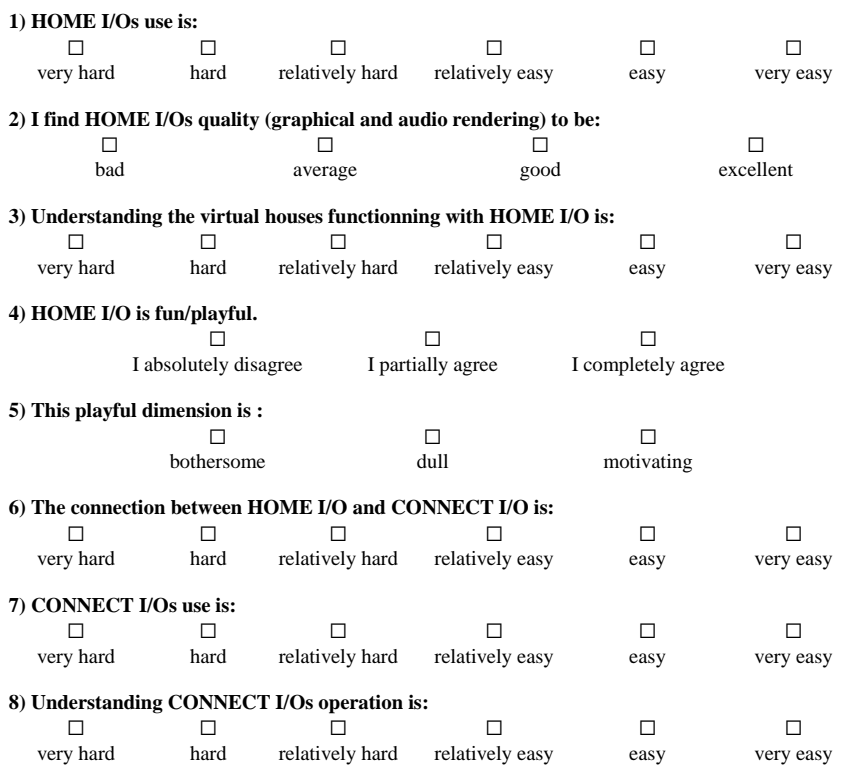

9) Did HOME I/O and CONNECT I/O help you understand these concepts seen during classes :

$\begin{array}{cccc}\text { Plant } & \square & \square & \square \\ & \text { no } & \text { partially } & \text { yes } \\ \text { Command part } & \square & \square & \square \\ \text { Combinatory and } & \text { no } & \text { partially } & \text { yes } \\ \text { sequential logic } & \square & \square & \square \\ & \text { no } & \text { partially } & \text { yes } \\ \text { Sensors } & & & \\ & \square & \square & \square \\ \text { Actuators } & \text { no } & \text { partially } & \text { yes } \\ & \square & \square & \square \\ & \text { no } & \text { partially } & \text { yes }\end{array}$

$\begin{array}{cc}\text { 10) Do you play videogames ? } \\ \square & \square \\ \text { no } & \text { yes }\end{array}$

If you chose yes, estimate how many hours a week you play, and tell us which ones you appreciate most

11) Do you have any additional remarks or suggestions on the use of FACTORY I/O and CONTROL I/O in practical courses ?

fig 5: French questions on HOME I/O and CONNECT I/O

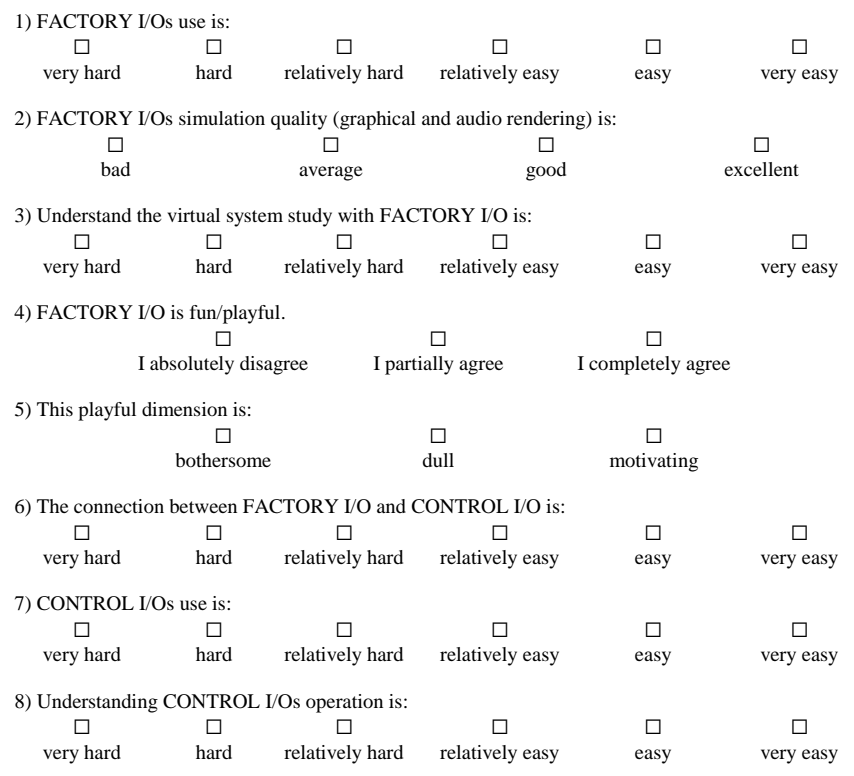

9) Did FACTORY I/O and CONTROL I/O help you understand these concepts seen during classes: Plant

$$
\begin{gathered}
\text { Command part } \\
\text { Combinatory and } \\
\text { sequential logic } \\
\text { Sensors }
\end{gathered}
$$

$\square$
no
$\square$
no
$\square$
no
$\square$
$\square$
no
$\square$

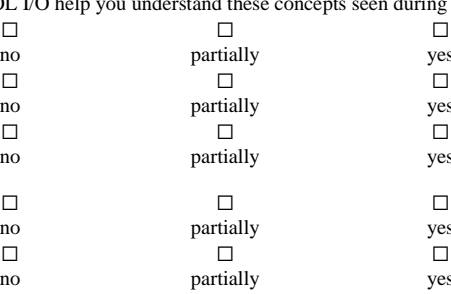

Do you have any additional remarks or suggestions on the use of FACTORY I/O and CONTROL $1 / 0$ in practical courses?

fig 6: French questions on FACTORY I/O and CONTROL I/O

On the point of the playing aspect more specifically: $86 \%$ of students consider this aspect to be motivating. It's interesting to observe that the 3 students which find the fun aspect to be a bother also consider these programs as fun. These 3 users didn't have any difficulties with the software, but there is a point about the way to learn things which would be interesting to explore beforehand. On the other hand, 4 of the 6 students which considered the fun aspect to be completely uninteresting had issues getting used to the programs. The profile of the students most likely corresponds to inexperienced users in this case, who didn't have the leisure to pronounce themselves on this aspect, as they had to solve technical questions.

As for Utility: every aspect (plant, command part, combinatory and sequential logic, sensors, actuators) are used by both programs (between $93 \%$ and $100 \%$ of students testify having at least partially used these concepts, figure 7). 


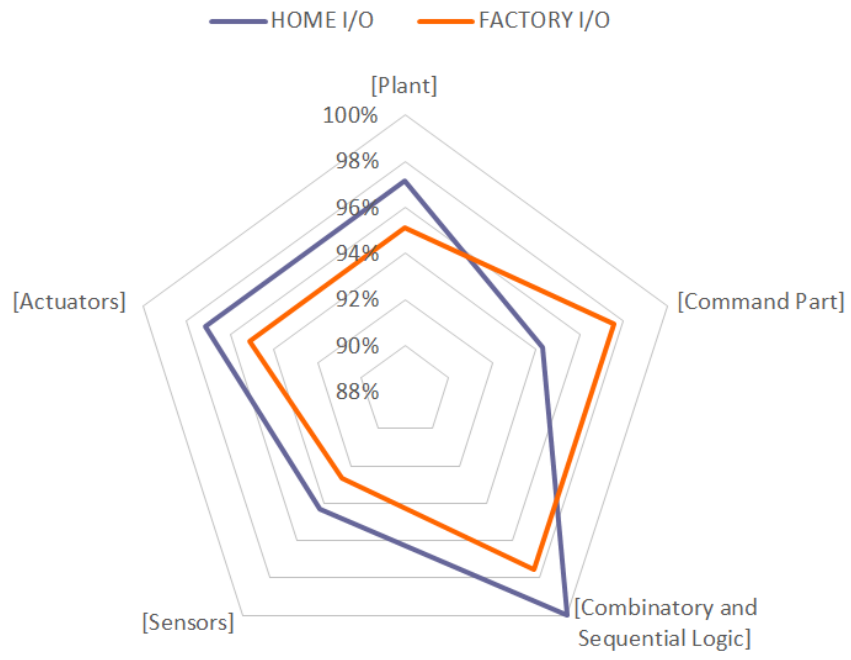

fig 7: Understanding dimensions or concepts

Asides from the command part, HOME $\mathrm{I} / \mathrm{O}$ is seen by students as working with all these concepts. It is indeed noteworthy that HOME I/O is seen as working completely with all of the concepts whereas FACTORY I/O is seen more as working partially with them. It is however appropriate to take these results considering that the students don't necessarily perceive all the dimensions, perception which can be partial for HOME I/O.

It is also noteworthy that the 3 teachers were using HOME I/O or FACTORY I/O for the very first time in practical courses. They have found that students didn't have any issues appropriating these programs and that the motivation of students was present. The results of this first feedback are positive and show that students were able to appropriate these simulation programs which contributed to the situational awareness, helping the learning process and decision making.

\section{CONCLUSION}

Several analogies can be made between the evolution of the education and the level of automation [7]. With today's technologies, the tendency is to remove the teacher from education. MOOCs (Massive Open Online Courses), blended learning... are experimented all over the world. Our approach on the education of automation through digital tools like serious games is different. The idea is not to remove the teacher from the training loop, but to develop simulation software using video game technology (FPS): 3D, graphical quality, audio rendering... HOME I/O and FACTORY I/O offer a practical, immersive and motivating experience for the education of automation. With HOME I/O and FACTORY I/O, the teacher is the Game Master. One of the big challenges is the training of the 4.0 industry and the plant of the future training. The two world of IT (Information Technologies) and OT (Operational Technologies) are joining together. Simulation tools such as HOME I/O and FACTORY I/O are able to contribute to linking these two fields by giving teachers and students system simulations that are dynamic, realistic, open and fun.

\section{REFERENCES}

[1] F. Arango, E-S. Aziz, S.K. Esche and C. Chassapis. «A review of applications of computer games in education and training », Frontiers in Edu. Conf.. Pp. T4A.1-4A.6, 2008.

[2] M.J. Mayo. «Video Games: A Route to Large-Scale STEM Education? », Science. 2009 Jan 2; 323(5910):79-82. doi: 10.1126/science.1166900.

[3] B. Riera, F. Emprin, D. Annebicque, M. Colas, B. Vigario. «HOME I/O: a virtual house for control and STEM education from middle schools to Universities ». 11th IFAC Symposium on Advances in Control Education ACE 2016, Bratislava (Slovakia), 1-3 June 2016.

[4] B. Riera, B. Vigario, J-P. Chemla, L. Correia and F. Gellot. « 10 ans de Maquettes Virtuelles pour l'enseignement des automatismes : de WINSIM en 1998 à ITS PLC PE en 2008 », J3eA 8 (HORS SÉRIE 1) 1004 (2009).

[5] F. Emprin, and B. Riera. «Process of creating educational uses by teachers from a 3D simulation of a house home automation to teach technology ». Proceedings of the 3rd international constructionism conference, August 19-23, 2014, pp. 247-257. Vienne, Austria.

[6] A. Tricot, F. Plégat-Soutjis, J-F. Camps, A. Amiel, and G. Lutz «Utilité, utilisabilité, acceptabilité : interpréter les relations entre trois dimensions de l'évaluation des EIAH. », Environnements Informatiques pour l'Apprentissage Humain 2003, Apr 2003, Strasbourg, France. ATIEF ; INRP, pp.391-402.

[7] L. Bainbridge. «Ironies of automation ». Automatica, vol 19, $N^{\circ} 6$, pp.775-779. 